\title{
Review Article \\ The Impact of Sleeve Gastrectomy on Hyperlipidemia: A Systematic Review
}

\author{
Khalid Al Khalifa, ${ }^{1}$ Ahmed Al Ansari, ${ }^{1}$ Abdul Rahim Alsayed, ${ }^{1}$ and Claudio Violato ${ }^{2}$ \\ ${ }^{1}$ Department of General Surgery, Bahrain Defense Force Hospital, Off Waly Alahed Avenue, P.O. Box 28743, West Riffa, Bahrain \\ ${ }^{2}$ Medical Education and Research Unit, Department of Community Health Sciences, Faculty of Medicine, University of Calgary, \\ Calgary, Canada
}

Correspondence should be addressed to Ahmed Al Ansari; drahmedalansari@gmail.com

Received 9 July 2013; Revised 5 September 2013; Accepted 5 September 2013

Academic Editor: B. J. Ammori

\begin{abstract}
Copyright (C) 2013 Khalid Al Khalifa et al. This is an open access article distributed under the Creative Commons Attribution License, which permits unrestricted use, distribution, and reproduction in any medium, provided the original work is properly cited.

Background. Weight loss and reduction in comorbidities can be achieved by longitudinal sleeve gastrectomy (LSG). Existing evidence suggests that LSG resolves or improves hyperlipidemia in morbidly obese patients. The aim of this study was to systematically review the effect of LSG on hyperlipidemia. Methods. A systematic literature search was conducted from Englishlanguage studies published from 2000 to 2012 for the following databases: MEDLINE, EMBASE, CINAHL, PubMed, Clinical evidence, Scopus, Dara, Web of Sciences, TRIP, Health Technology Database, Cochrane library, and PsycINFO. Results. A total of 4,211 articles were identified in the initial search, and 4,185 articles were excluded based on the exclusion criteria. Twenty-six studies met the inclusion criteria for this systematic review, involving 3,591 patients. The mean preoperative body mass index (BMI) was $48 \pm 7.0 \mathrm{~kg} / \mathrm{m}^{2}$ (range 37.2-65.3). The mean postoperative BMI was $35 \pm 5.9 \mathrm{~kg} / \mathrm{m}^{2}$ (range 26.3-49). The mean percentage of excess weight loss (EWL) was 63.1\% (range 37.7-84.5), with a mean followup of 19.1 months (range 6-60). The mean levels of pre and post operative cholesterol were $194.4 \pm 12.3 \mathrm{mg} / \mathrm{dL}$ (range 178-213) and $181 \pm 16.3 \mathrm{mg} / \mathrm{dL}$ (range 158-200), respectively. Conclusion. Most patients with hyperlipidemia showed improvement or resolution of lipid profiles after LSG. Based on this systematic review, LSG has a significant effect on hyperlipidemia in the form of resolution or improvement in the majority of patients.
\end{abstract}

\section{Introduction}

Laparoscopic sleeve gastrectomy (LSG) was introduced initially as a first stage of the biliopancreatic diversion with duodenal switch (BPDDS) for severely obese patients who were regarded as high risk surgical candidates [1]. Due to its greater efficiency [2], technical simplicity [3], and low complication rates [4], LSG has become more widely accepted as a definitive treatment for morbidly obese patients [5]. In LSG, the stomach is divided vertically, while removing most of the fundus of the stomach and preserving the continuity of the digestive tract [6].

LSG leads to long-term weight loss and improvement or resolution of its associated comorbidities such as diabetes mellitus (DM), hypertension, and hyperlipidemia $[7,8]$. In a recent systematic review on the effect of the LSG on co-morbidities, Sarkhosh et al. [8] reported resolution of hypertension in 58\% and resolution or improvement of hypertension in $75 \%$ of patients following LSG. In another systematic review, Alamo et al. [9] reported resolution of type 2 diabetes mellitus (T2DM) in $84 \%$ of patients after LSG. To our knowledge, the effect of LSG on hyperlipidemia was not reviewed systematically.

Most patients with obesity present with lipid abnormalities; however, only $20 \%$ of the obese patients population are not showing classical metabolic lipid changes [10]. Patients with abdominal obesity are more likely to have atherogenic dyslipidemia than those who have increased levels of the Low density lipoprotein (LDL) [11]. Hyperlipidemia is widely recognized as one of the main co-morbidities in severe obesity. It is therefore not surprising that research and treatment are increasingly focused on lipid profiles in the drive to potentially reduce cardiovascular related-diseases [12, 13]. The aim of this study is therefore to systematically review the 


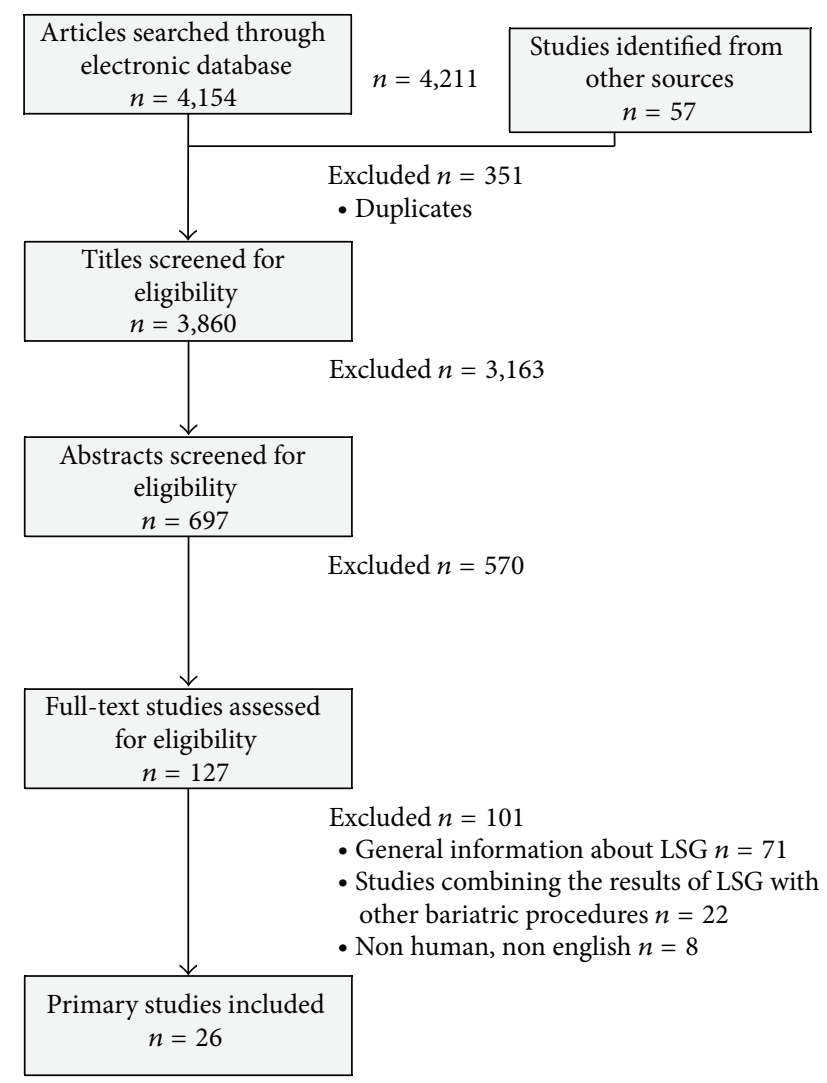

FIGURE 1: Flow chart showing systematic review search. LSG = longitudinal sleeve gastrectomy.

published data regarding the effect of LSG on resolution or improvement of hyperlipidemia in obese patients.

\section{Methods}

2.1. Search Strategy. A systematic literature search was conducted from English-language studies published from 2000 to 2012 for the following databases: MEDLINE, EMBASE, CINAHL, PubMed, Clinical Evidence, Scopus, Dara, Web of Sciences, TRIP, Health Technology Database, Cochrane library, and PsycINFO. The potential articles from the reference lists of selected articles were searched as well. "Gray literature," including conference abstracts, registered clinical trials, and websites was searched, including the Conference Papers Index and the Online Computer Library Center (OCLC) Papers First. The following terms were used in the search: gastric sleeve, effect of gastric sleeve on hyperlipidemia, sleeve gastrectomy, and the effect of gastric sleeve on co morbidities.

2.2. Data Collection and Quality Assessment. Studies of any design involving LSG for obese patients with hyperlipidemia from January 2000 to December 2012 were considered. Two independent authors then assessed the studies for relevance, inclusion, and methodological quality. The studies were classified as relevant (meeting all of the inclusion criteria), possibly relevant (meeting some but not all of the inclusion criteria), and rejected (not relevant to our review and not meeting the inclusion criteria). Each article in this study was evaluated by 2 authors independently based on the title and abstract classified as relevant or possibly relevant. Any disagreements about relevance were solved by a third coder. Based on discussions among the three coders, we achieved $100 \%$ agreement on the studies to be included.

The initial search yielded 4,211 articles as described in Figure 1. Of these, 351 were duplicates, 3,163 articles were excluded based on the title, further 570 articles were excluded based on the abstract, and another 101 studies were eliminated after reading the full paper. Finally, we agreed on 26 articles to be included in the present systematic review.

2.3. Outcome Measures. Studies included in this systematic review were LSG either as a single procedure or as a first procedure of staged surgery. The primary outcome of this study was resolution or improvement of hyperlipidemia. The resolution of hyperlipidemia was defined as discontinuation of all hyperlipidemia medications. The improvement of hyperlipidemia was defined as dose reduction of lipid lowering medications. The secondary outcome included changes in body mass index (BMI) postoperatively and the percentage of excess weight loss (\%EWL). However, (\% EWL) was calculated as follows: $\%$ EWL $)=($ weight loss/excess weight) $\times 100$, where excess weight is the total preoperative weight minus the ideal weight [14]. Ideal weight is the desirable weight which would indicate those persons with the lowest mortality rates and can be calculated through the metropolitan life table which is based on height, weight, and gender.

2.4. Selection Criteria. Studies were included if they (1) were studies of any design that involved LSG, (2) included reports on the effect of LSG on lipid profile, (3) compared LSG versus any other type of bariatric surgery, (4) were studies where a second stage procedure was planned, (5) reported data on cholesterol, triglyceride, LDL, and high density lipoprotein (HDL), (6) were published in English in peer-reviewed journals, and (7) were classified as relevant or possibly relevant based on two independent authors.

We excluded studies if (1) repeated LSG was performed, (2) they were conducted on patients who participated in health and/or nutrition program, (3) they provided only general descriptions and information about LSG without empirical data, (4) they combined LSG with another bariatric procedure results, (5) LSG was performed as revision surgery, (6) they provided information on the effect of LSG on other co-morbidities, and (7) they were nonhuman and nonEnglish studies.

2.5. Assessment of Risk of Bias in Included Studies. All included studies were assessed independently by two authors for methodological quality using the Cochrane and risk of bias tools [15]. 


\section{Results}

3.1. Search Results. As summarized in Figure 1, we agreed on 26 articles to be included in the present study. These included 18 retrospective clinical studies, 7 prospective clinical studies, and one randomized clinical trial. Five studies were published in 2012. Eight studies were published in 2011. Another seven studies were published in 2010 and two studies were published in 2008. One study was published in 2005, 2006, and 2007 (Table 1) [16-41].

3.2. Results of the Effects of LSG on Hyperlipidemia. All of the 26 studies reported LSG-associated outcomes data on lipid profile-related measurements, BMI, excess weight loss and duration of followup. A total of 3,591 patients were assessed in the 26 studies. The number of patients ranged from 20 to 944. The average age of patients was $42.35 \pm 5.14$ years (range $30-49.5)$. Female represented $68.9 \%$ of the total patients. The mean preoperative BMI was $48 \pm 7.0 \mathrm{~kg} / \mathrm{m}^{2}$ (range 37.2-65.3). The mean postoperative BMI was $35 \pm 5.9 \mathrm{~kg} / \mathrm{m}^{2}$ (range $26.3-$ 49). The mean percentage of excess weight loss was $63.1 \%$ (range 37.7-84.5), with a mean followup of 19.1 months (range 6-60) (Table 1).

The mean levels of pre- and postoperative cholesterol were $194.4 \pm 12.3 \mathrm{mg} / \mathrm{dL}$ (range 178-213), and $181 \pm 16.3 \mathrm{mg} / \mathrm{dL}$ (range 158-200), respectively. The mean levels of pre- and postoperative triglyceride were $149.3 \pm 21.2 \mathrm{mg} / \mathrm{dL}$ (range 120-174) and $102 \pm 14.2 \mathrm{mg} / \mathrm{dL}$ (range 84-116), respectively. The mean levels of pre- and postoperative LDL were 121.3 $\pm 10.3 \mathrm{mg} / \mathrm{dL}$ (range 109-138) and $112 \pm 3.3 \mathrm{mg} / \mathrm{dL}$ (range 109-117), respectively, and the mean levels of pre- and postoperative HDL were $46.4 \pm 2.8 \mathrm{mg} / \mathrm{dL}$ (range 42-49), and $54 \pm 9.3 \mathrm{mg} / \mathrm{dL}$ (range 43-64), respectively.

Within the 26 studies included in this systematic review, 11 reported both resolution and improvement of hyperlipidemia after LSG and $83.5 \%$ of the patients had experienced resolution or improvement of hyperlipidemia. Another 7 studies reported only hyperlipidemia resolution and 54\% of patients had complete resolution of hyperlipidemia. One study reported improvement of hyperlipidemia in $42 \%$ of the patients.

Five studies compared the lipid profile results pre and post-surgery $[19,23,37,39,41]$. Only three studies showed minimal changes between pre and post operative cholesterol and LDL levels $[18,19,41]$. However, the same three studies reported significant changes in triglyceride level and HDL level post LSG (Table 2).

\section{Discussion}

The main purpose of this systematic review was to investigate further the effect of LSG on hyperlipidemia. LSG was initially used as a first stage operation for high risk surgical patients prior to undergoing a gastric bypass or biliopancreatic diversion. Existing evidence has suggested that LSG is effective as a single procedure for the treatment of morbid obesity and improvement or resolution of co-morbidities.
Our systematic review showed that LSG resolved or improved hyperlipidemia in a majority of patients. $83.5 \%$ of patients had resolution or improvement of their hyperlipidemia and 54\% experienced complete resolution of their hyperlipidemia. These results correspond with other bariatric procedures. Omana et al. [32] found a greater resolution or improvement of hyperlipidemia with LSG in comparison with laparoscopic adjustable gastric banding. Hyperlipidemia improved in $87 \%$ of patients after LSG and in $50 \%$ of patients after gastric banding after a 15-month followup period.

Benaiges et al. [19] reported lower improvement or resolution rates for hyperlipidemia in the LSG group than in the laparoscopic Roux-en-Y gastric bypass (LRYGB). The hyperlipidemia improvement or resolution rate was $100 \%$ for LRYGB versus 75\% for LSG. Researchers argued that the decrease in LDL cholesterol observed for LRYGB could be related to the malabsorption effect produced by this technique. This hypothesis is supported by several data [14, 42].

Similarly, Kehagias et al. [28] found less resolution of hyperlipidemia in patients after LSG versus patients who underwent LRYGB. The rate of hyperlipidemia resolution was $90 \%$ for patients who had LRYGB and $75 \%$ for patients who had LSG. Lakdawala et al. [29] reported almost similar results for patients who had LSG and patients who had LRYGB. At one-year followup, hyperlipidemia resolved in $75 \%$ of patients who underwent LSG and in $78 \%$ of those who underwent LRYGB. Skroubis et al. [36] reported 90\%, $78.4 \%, 55 \%$, and $48.7 \%$ resolutions of hyperlipidemia after a 5-year followup for patients who underwent biliopancreatic diversion, vertical banded plasty, LSG, and Roux-en-Y gastric bypass (RYGB) respectively.

In regard to the secondary outcome, our systematic review showed a reduction in the $\%$ EWL over a one-year followup. The percentage of EWL after LSG was 63.1\% (range 37.7-84.5). In comparison with other bariatric procedures, Kehagias et al. [28] reported greater loss of the \%EWL in the LSG group in the first 2 years of their study and greater in the third year but with no statistical significance. Kehagias et al. [28] went further and found that the proportion of patients who achieved a \%EWL greater than $50 \%$ at 3 years postoperatively was 77\% after LRYGB and $83 \%$ after LSG.

Omana et al. [32] reported greater loss of \%EWL with LSG being $50.6 \%$ versus $40.3 \%$ with laparoscopic adjustable gastric banding. Lakdawala et al. [29] reported 50.5\% loss of \%EWL 6 months after LSG versus $41.7 \%$ loss of \%EWL after LRYGB.

\section{Limitation}

The primary studies included in this systematic review were case series and nonrandomized controlled trials, which are inherently biased. There were no published randomized controlled studies comparing LSG and medical therapy assessments of the resolution of hyperlipidemia on obese patients. Given this fact, the result of our systematic review should be interpreted with caution to avoid misleading results. This fact, however, appears to be applied to the majority of bariatric 
TABLE 1: Baseline characteristics within included studies for systematic review.

\begin{tabular}{|c|c|c|c|c|c|c|c|c|}
\hline Investigator & Study design & Patient $n$ & $\begin{array}{c}\text { Mean age } \\
\text { (year) }\end{array}$ & Gender (\% F) & $\begin{array}{c}\text { Mean BMI } \\
\left(\mathrm{kg} / \mathrm{m}^{2}\right)\end{array}$ & Surgery & $\begin{array}{l}\text { Post-op } \\
(\mathrm{BMI})\end{array}$ & $\begin{array}{c}\text { Followup period } \\
\text { (months) }\end{array}$ \\
\hline $\begin{array}{l}\text { Abbatini et al. } \\
{[16], 2010}\end{array}$ & RCS & 20 & 46.6 & $60.00 \%$ & 51.6 & LSG & & 36 \\
\hline $\begin{array}{l}\text { Atkins et al. [17], } \\
2012\end{array}$ & RCS & 291 & 45.8 & $76.90 \%$ & 42.2 & LSG & & 48 \\
\hline $\begin{array}{l}\text { Benaiges et al. } \\
{[18], 2011}\end{array}$ & PCS & 45 & 44.1 & $78.60 \%$ & 44.6 & LSG & 28.9 & 12 \\
\hline $\begin{array}{l}\text { Benaiges et al. } \\
{[19], 2012}\end{array}$ & PCS & 51 & 44.5 & $82.30 \%$ & 44.6 & LSG & 28.5 & 12 \\
\hline $\begin{array}{l}\text { Boza et al. [20], } \\
2012\end{array}$ & RCS & 773 & 36.9 & $100 \%$ & 37.4 & LSG & 27.2 & 12 \\
\hline $\begin{array}{l}\text { Cottam et al. } \\
{[21], 2006}\end{array}$ & PCS & 126 & 49.5 & $53.00 \%$ & 65.3 & LSG & 49.0 & 12 \\
\hline $\begin{array}{l}\text { Chowbey et al. } \\
{[22], 2010}\end{array}$ & RCS & 75 & 44.4 & $53.30 \%$ & 58.0 & LSG & 37.7 & 12 \\
\hline $\begin{array}{l}\text { Hady et al. [23], } \\
2012\end{array}$ & RCS & 100 & 47.9 & $52.00 \%$ & 52.2 & LSG & 38.0 & 6 \\
\hline $\begin{array}{l}\text { D’Hondt et al. } \\
\text { [24], } 2011\end{array}$ & RCS & 83 & 40.4 & $73.50 \%$ & 39.3 & LSG & & 12 \\
\hline $\begin{array}{l}\text { Han et al. [25], } \\
2005\end{array}$ & RCS & 60 & 30.0 & $86.70 \%$ & 37.2 & LSG & 28.0 & 12 \\
\hline $\begin{array}{l}\text { Hutter et al. } \\
{[26], 2011}\end{array}$ & RCS & 944 & 46.5 & $75.00 \%$ & 46.2 & LSG & 34.4 & 12 \\
\hline $\begin{array}{l}\text { Kasama et al. } \\
{[27], 2008}\end{array}$ & RCS & 23 & 38.0 & $26.10 \%$ & 49.1 & LSG & 42.1 & 12 \\
\hline $\begin{array}{l}\text { Kehagias et al. } \\
{[28], 2011}\end{array}$ & RCT & 30 & 33.7 & $73.30 \%$ & 44.9 & LSG & & 36 \\
\hline $\begin{array}{l}\text { Lakdawala et al. } \\
\text { [29], } 2010\end{array}$ & RCS & 50 & 38.0 & $52.00 \%$ & 46.0 & LSG & 26.3 & 12 \\
\hline $\begin{array}{l}\text { Leivonen et al. } \\
\text { [30], } 2011\end{array}$ & PCS & 55 & 48.5 & $69.00 \%$ & 49.5 & LSG & 38.2 & 12 \\
\hline $\begin{array}{l}\text { Nienhuijs et al. } \\
{[31], 2010}\end{array}$ & PCS & 74 & 42.0 & $60.80 \%$ & 51.0 & LSG & 39.2 & 12 \\
\hline $\begin{array}{l}\text { Omana et al. } \\
{[32], 2010}\end{array}$ & RCS & 49 & 45.0 & $73.50 \%$ & 52.0 & LSG & 37.8 & 12 \\
\hline $\begin{array}{l}\text { Prasad et al. } \\
{[33], 2012}\end{array}$ & RCS & 108 & 39.3 & $76.40 \%$ & 44.5 & LSG & 30.2 & 36 \\
\hline $\begin{array}{l}\text { Ramalingam } \\
\text { and Anton [34], } \\
2011\end{array}$ & RCS & 20 & 43.6 & $45.00 \%$ & 42.5 & LSG & 33.1 & 12 \\
\hline $\begin{array}{l}\text { Sammour et al. } \\
{[35], 2010}\end{array}$ & PCS & 100 & 43.0 & $80.00 \%$ & 50.3 & LSG & & 12 \\
\hline $\begin{array}{l}\text { Skroubis et al. } \\
{[36], 2011}\end{array}$ & RCS & 151 & 32.8 & & 43.1 & LSG & & 60 \\
\hline $\begin{array}{l}\text { Todkar et al. } \\
\text { [37], } 2010\end{array}$ & RCS & 23 & 44.6 & $73.90 \%$ & 40.7 & LSG & 30.9 & 36 \\
\hline $\begin{array}{l}\text { Weiner et al. } \\
{[38], 2007}\end{array}$ & RCS & 120 & 40.3 & $71.60 \%$ & 60.7 & LSG & 38.0 & 12 \\
\hline $\begin{array}{l}\text { Wong et al. [39], } \\
2011\end{array}$ & RCS & 37 & 46.0 & $78.40 \%$ & 46.0 & LSG & 33.0 & 9.2 \\
\hline $\begin{array}{l}\text { Ou Yang et al. } \\
{[40], 2008}\end{array}$ & PCS & 138 & & $64.50 \%$ & 50.6 & LSG & 39.8 & 24 \\
\hline $\begin{array}{l}\text { Strain et al. [41], } \\
2011\end{array}$ & RCS & 45 & 47.3 & $85.00 \%$ & 57.5 & LSG & 39.9 & 12 \\
\hline Mean/total & & 3591 & 42.3 & $68.90 \%$ & 48.0 & & 35.0 & 19.1 \\
\hline
\end{tabular}

RCS: retrospective clinical study, LSG: laparoscopic sleeve surgery, PCS: prospective clinical study, BMI: body mass index, and RCT: randomized clinical trial. 
TABLE 2: Laparoscopic sleeve gastrectomy outcomes: systematic review.

\begin{tabular}{|c|c|c|c|c|c|c|c|c|c|c|c|c|c|}
\hline \multirow{2}{*}{ Investigator } & \multirow{2}{*}{$\begin{array}{l}\text { No of patients with } \\
\uparrow \text { lipid }\end{array}$} & \multicolumn{2}{|c|}{ Cholesterol } & \multicolumn{2}{|c|}{ Triglyceride } & \multicolumn{2}{|c|}{ LDL } & \multicolumn{2}{|c|}{ HDL } & \multirow{2}{*}{ EWL \% } & \multicolumn{2}{|c|}{ Results (number or \%) } & \multirow{2}{*}{ Sta } \\
\hline & & Pre & Post & Pre & Post & Pre & Post & Pre & Post & & Res & $\operatorname{Imp}$ & \\
\hline $\begin{array}{l}\text { Abbatini et al. [16], } \\
2010\end{array}$ & 7 & & & & & & & & & 68 & 2 & 26 & 6 \\
\hline $\begin{array}{l}\text { Atkins et al. [17], } \\
2012\end{array}$ & 50 & & & & & & & & & & & $42 \%$ & \\
\hline $\begin{array}{l}\text { Benaiges et al. [18], } \\
2011\end{array}$ & 12 & 194 & 200 & 133 & 86 & 120 & 117 & 49 & 63 & 82.7 & $75 \%$ & & \\
\hline $\begin{array}{l}\text { Benaiges et al. [19], } \\
2012\end{array}$ & 51 & 192 & 196 & 120 & 84 & 119 & 115 & 48 & 64 & & & & \\
\hline $\begin{array}{l}\text { Boza et al. [20], } \\
2012\end{array}$ & 112 & & & & & & & & & 84.5 & 95 & 11 & 6 \\
\hline $\begin{array}{l}\text { Cottam et al. [21], } \\
2006\end{array}$ & 65 & & & & & & & & & 46 & $73 \%$ & $5 \%$ & \\
\hline $\begin{array}{l}\text { Chowbey et al. } \\
{[22], 2010}\end{array}$ & 40 & 178 & 158 & 162 & 101 & & & & & 52.3 & 34 & & \\
\hline $\begin{array}{l}\text { Hady et al. [23], } \\
2012\end{array}$ & 100 & 213 & 182 & 166 & 116 & 138 & 111 & 42 & 43 & 49 & & & \\
\hline $\begin{array}{l}\text { D'Hondt et al. [24], } \\
2011\end{array}$ & 36 & & & & & & & & & 81.5 & 25 & 3 & \\
\hline $\begin{array}{l}\text { Han et al. [25], } \\
2005\end{array}$ & 20 & & & & & & & & & 83.3 & $65 \%$ & $10 \%$ & \\
\hline $\begin{array}{l}\text { Hutter et al. [26], } \\
2011\end{array}$ & 311 & & & & & & & & & & $35 \%$ & & \\
\hline $\begin{array}{l}\text { Kasama et al. [27], } \\
2008\end{array}$ & 9 & & & & & & & & & & 3 & 3 & \\
\hline $\begin{array}{l}\text { Kehagias et al. [28], } \\
2011\end{array}$ & 8 & & & & & & & & & 68.5 & 6 & & \\
\hline $\begin{array}{l}\text { Lakdawala et al. } \\
\text { [29], } 2010\end{array}$ & 50 & & & & & & & & & 76.1 & $75 \%$ & & \\
\hline $\begin{array}{l}\text { Leivonen et al. } \\
{[30], 2011}\end{array}$ & 18 & & 4.7 & & 3 & & 1.3 & & 1.4 & 49.2 & $15 \%$ & & 3 \\
\hline $\begin{array}{l}\text { Nienhuijs et al. } \\
{[31], 2010}\end{array}$ & 14 & & & & & & & & & 49.2 & $5 \%$ & 4 & 5 \\
\hline $\begin{array}{l}\text { Omana et al. [32], } \\
2010\end{array}$ & 15 & & & & & & & & & 37.7 & 13 & 2 & \\
\hline $\begin{array}{l}\text { Prasad et al. [33], } \\
2012\end{array}$ & 42 & & & & & & & & & 66.1 & $86 \%$ & $14 \%$ & \\
\hline $\begin{array}{l}\text { Ramalingam and } \\
\text { Anton [34], } 2011\end{array}$ & 4 & & & & & & & & & 49.6 & 3 & 1 & \\
\hline $\begin{array}{l}\text { Sammour et al. } \\
{[35], 2010}\end{array}$ & 25 & & & & & & & & & 62.9 & 5 & & 20 \\
\hline $\begin{array}{l}\text { Skroubis et al. [36], } \\
2011\end{array}$ & 26 & & & & & & & & & 52.7 & & & \\
\hline $\begin{array}{l}\text { Todkar et al. [37], } \\
2010\end{array}$ & 21 & 203 & 167 & 174 & 116 & 120 & 110 & 45 & 47 & 74.5 & & & \\
\hline $\begin{array}{l}\text { Weiner et al. [38], } \\
2007\end{array}$ & 34 & & & & & & & & & 68 & 2 & 26 & 6 \\
\hline $\begin{array}{l}\text { Wong et al. [39], } \\
2011\end{array}$ & 37 & 5.3 & 4.9 & 1.8 & 1.2 & 3.2 & 3 & 1.3 & 1.4 & & & & \\
\hline $\begin{array}{l}\text { Ou Yang et al. [40], } \\
2008\end{array}$ & 23 & & & & & & & & & 46.1 & $87 \%$ & & \\
\hline $\begin{array}{l}\text { Strain et al. [41], } \\
2011\end{array}$ & 25 & 186 & 186 & 141 & 109 & 109 & 110 & 48 & 54 & & & & \\
\hline Mean/total & 1,175 & 194 & 181 & 149 & 102 & 121 & 112 & 47 & 54 & 63.1 & & & \\
\hline
\end{tabular}


surgical data. Furthermore, a formal meta-analysis could not feasibly be conducted due to the high degree of heterogeneity in the study's design, intervention, and the population in the studies. With all these limitations, nevertheless, our review supports the idea that LSG is associated with the resolution and/or improvement of hyperlipidemia after LSG.

\section{Conclusion}

This systematic review shows that LSG has a significant effect on hyperlipidemia, producing resolution or improvement in most of the cases. Therefore, LSG remains a viable surgical option for weight loss and reduction in co-morbidities such as hyperlipidemia.

\section{Conflict of Interests}

The authors of this systematic review declare no conflict of interests of any kind.

\section{References}

[1] D. S. Hess and D. W. Hess, "Biliopancreatic diversion with a duodenal switch," Obesity Surgery, vol. 8, no. 3, pp. 267-282, 1998.

[2] E. Akkary, A. Duffy, and R. Bell, "Deciphering the sleeve: technique, indications, efficacy, and safety of sleeve gastrectomy," Obesity Surgery, vol. 18, no. 10, pp. 1323-1329, 2008.

[3] S. E. Greenway, F. L. Greenway III, and S. Klein, "Effects of obesity surgery on non-insulin-dependent diabetes mellitus," Archives of Surgery, vol. 137, no. 10, pp. 1109-1117, 2002.

[4] G. Silecchia, C. Boru, A. Pecchia et al., "Effectiveness of laparoscopic sleeve gastrectomy (first stage of biliopancreatic diversion with duodenal switch) on co-morbidities in superobese high-risk patients," Obesity Surgery, vol. 16, no. 9, pp. 1138$1144,2006$.

[5] S. Chiu, D. W. Birch, X. Shi, A. M. Sharma, and S. Karmali, "Effect of sleeve gastrectomy on gastroesophageal reflux disease: a systematic review," Surgery for Obesity and Related Diseases, vol. 7, no. 4, pp. 510-515, 2011.

[6] R. S. Gill, D. W. Birch, X. Shi, A. M. Sharma, and S. Karmali, "Sleeve gastrectomy and type 2 diabetes mellitus: a systematic review," Surgery for Obesity and Related Diseases, vol. 6, no. 6, pp. 707-713, 2010.

[7] T. A. Kotchen, "Obesity-related hypertension: epidemiology, pathophysiology, and clinical management," American Journal of Hypertension, vol. 23, no. 11, pp. 1170-1178, 2010.

[8] K. Sarkhosh, D. W. Birch, X. Shi, R. S. Gill, and S. Karmali, “The impact of sleeve gastrectomy on hypertension: a systematic review," Obesity Surgery, vol. 22, pp. 832-837, 2012.

[9] M. Alamo, M. Sepúlveda, J. Gellona, M. Herrera, C. Astorga, and C. Manterola, "Sleeve gastrectomy with jejunal bypass for the treatment of type 2 diabetes mellitus in patients with body mass index $<35 \mathrm{~kg} / \mathrm{m}^{2}$. A Cohort Study," Obesity Surgery, vol. 22, pp. 1097-1103, 2012.

[10] A. D. Karelis, D. H. St-Pierre, F. Conus, R. Rabasa-Lhoret, and E. T. Poehlman, "Metabolic and body composition factors in subgroups of obesity: what do we know?" Journal of Clinical Endocrinology and Metabolism, vol. 89, no. 6, pp. 2569-2575, 2004.
[11] S. M. Grundy, "Atherogenic dyslipidemia: lipoprotein abnormalities and implications for therapy," American Journal of Cardiology, vol. 75, no. 6, pp. 45B-52B, 1995.

[12] M. Vila, O. Ruíz, M. Belmonte et al., "Changes in lipid profile and insulin resistance in obese patients after Scopinaro biliopancreatic diversion," Obesity Surgery, vol. 19, no. 3, pp. 299-306, 2009.

[13] N. T. Nguyen, E. Varela, A. Sabio, C.-L. Tran, M. Stamos, and S. E. Wilson, "Resolution of hyperlipidemia after laparoscopic Roux-en-Y gastric bypass," Journal of the American College of Surgeons, vol. 203, no. 1, pp. 24-29, 2006.

[14] H. Buchwald, Y. Avidor, E. Braunwald et al., "Bariatric surgery: a systematic review and meta-analysis," Journal of the American Medical Association, vol. 292, no. 14, pp. 1724-1737, 2004.

[15] J. P. Higgins and S. Green, Eds., Cochrane Handbook for Systematic Reviews of Interventions, John Wiley \& Sons, London, UK, 2008.

[16] F. Abbatini, M. Rizzello, G. Casella et al., "Long-term effects of laparoscopic sleeve gastrectomy, gastric bypass, and adjustable gastric banding on type 2 diabetes," Surgical Endoscopy and Other Interventional Techniques, vol. 24, no. 5, pp. 1005-1010, 2010.

[17] E. R. Atkins, D. B. Preen, C. Jarman, and L. D. Cohen, "Improved obesity reduction and co-morbidity resolution in patients treated with 40 -french bougie versus 50 -french bougie four years after laparoscopic sleeve gastrectomy. Analysis of 294 patients," Obesity Surgery, vol. 22, no. 1, pp. 97-104, 2012.

[18] D. Benaiges, A. Goday, J. M. Ramon, E. Hernandez, M. Pera, and J. F. Cano, "Laparoscopic sleeve gastrectomy and laparoscopic gastric bypass are equally effective for reduction of cardiovascular risk in severely obese patients at one year of follow-up," Surgery for Obesity and Related Diseases, vol. 7, no. 5, pp. 575$580,2011$.

[19] D. Benaiges, J. A. Flores-Le-Roux, J. Pedro-Botet et al., "Impact of restrictive (Sleeve Gastrectomy) vs hybrid bariatric surgery (Roux-en-Y Gastric Bypass) on lipid profile," Obesity Surgery, vol. 22, pp. 1268-1275, 2012.

[20] C. Boza, J. Salinas, N. Salgado et al., "Laparoscopic sleeve gastrectomy as a stand-alone procedure for morbid obesity: report of 1,000 cases and 3-year follow-up," Obesity Surgery, vol. 22, pp. 866-871, 2012.

[21] D. Cottam, F. G. Qureshi, S. G. Mattar et al., "Laparoscopic sleeve gastrectomy as an initial weight-loss procedure for highrisk patients with morbid obesity," Surgical Endoscopy and Other Interventional Techniques, vol. 20, no. 6, pp. 859-863, 2006.

[22] P. K. Chowbey, K. Dhawan, R. Khullar et al., "Laparoscopic sleeve gastrectomy: an indian experience-surgical technique and early results," Obesity Surgery, vol. 20, no. 10, pp. 1340-1347, 2010.

[23] H. Hady, P. Golaszewaski, R. L. Zbucki et al., "The influence of laparoscopic adjustable gastric banding and laparoscopic sleeve gastectomy on weight loss, plasma ghrelin, insulin, glucose and lipids," Folia Hiosto Chemica, vol. 50, pp. 292-303, 2012.

[24] M. D’Hondt, S. Vanneste, H. Pottel, D. Devriendt, F. Van Rooy, and F. Vansteenkiste, "Laparoscopic sleeve gastrectomy as a single-stage procedure for the treatment of morbid obesity and the resulting quality of life, resolution of comorbidities, food tolerance, and 6-year weight loss," Surgical Endoscopy and Other Interventional Techniques, vol. 25, no. 8, pp. 2498-2504, 2011.

[25] S. M. Han, W. W. Kim, and J. H. Oh, "Results of laparoscopic sleeve gastrectomy (LSG) at 1 year in morbidly obese Korean patients," Obesity Surgery, vol. 15, no. 10, pp. 1469-1475, 2005. 
[26] M. M. Hutter, B. D. Schirmer, D. B. Jones et al., "First report from the American College of Surgeons Bariatric Surgery Center Network: laparoscopic sleeve gastrectomy has morbidity and effectiveness positioned between the band and the bypass," Annals of Surgery, vol. 254, no. 3, pp. 410-422, 2011.

[27] K. Kasama, N. Tagaya, E. Kanahira et al., "Has laparoscopic bariatric surgery been accepted in Japan? The experience of a single surgeon," Obesity Surgery, vol. 18, no. 11, pp. 1473-1478, 2008.

[28] I. Kehagias, S. N. Karamanakos, M. Argentou, and F. Kalfarentzos, "Randomized clinical trial of laparoscopic Roux-en-Y gastric bypass versus laparoscopic sleeve gastrectomy for the management of patients with $\mathrm{BMI}<50 \mathrm{~kg} / \mathrm{m}^{2}$," Obesity Surgery, vol. 21, no. 11, pp. 1650-1656, 2011.

[29] M. A. Lakdawala, A. Bhasker, D. Mulchandani, S. Goel, and S. Jain, "Comparison between the results of laparoscopic sleeve gastrectomy and laparoscopic roux-en-y gastric bypass in the Indian population: a retrospective 1 year study," Obesity Surgery, vol. 20, no. 1, pp. 1-6, 2010.

[30] M. K. Leivonen, A. Juuti, N. Jaser, and H. Mustonen, "Laparoscopic sleeve gastrectomy in patients over 59 years: early recovery and 12-month follow-up," Obesity Surgery, vol. 21, no. 8, pp. 1180-1187, 2011.

[31] S. W. Nienhuijs, J. P. de Zoete, C. A. S. Berende, I. H. J. T. de Hingh, and J. F. Smulders, "Evaluation of laparoscopic sleeve gastrectomy on weight loss and co-morbidity," International Journal of Surgery, vol. 8, no. 4, pp. 302-304, 2010.

[32] J. J. Omana, S. Q. Nguyen, D. Herron, and S. Kini, "Comparison of comorbidity resolution and improvement between laparoscopic sleeve gastrectomy and laparoscopic adjustable gastric banding," Surgical Endoscopy and Other Interventional Techniques, vol. 24, no. 10, pp. 2513-2517, 2010.

[33] P. Prasad, O. Tantia, N. Patle, S. Khanna, and B. Sen, "An analysis of 1-3-year Follow-up results of laparoscopic sleeve gastrectomy: an indian perspective," Obesity Surgery, vol. 22, no. 3, pp. 507-514, 2012.

[34] G. Ramalingam and C. K. S. Anton, "Our 1-year experience in laparoscopic sleeve gastrectomy," Obesity Surgery, vol. 21, no. 12, pp. 1828-1833, 2011.

[35] T. Sammour, A. G. Hill, P. Singh, A. Ranasinghe, R. Babor, and H. Rahman, "Laparoscopic sleeve gastrectomy as a single-stage bariatric procedure," Obesity Surgery, vol. 20, no. 3, pp. 271-275, 2010.

[36] G. Skroubis, S. Karamanakos, G. Sakellaropoulos, K. Panagopoulos, and F. Kalfarentzos, "Comparison of early and late complications after various bariatric procedures: incidence and treatment during 15 years at a single institution," World Journal of Surgery, vol. 35, no. 1, pp. 93-101, 2011.

[37] J. S. Todkar, S. S. Shah, P. S. Shah, and J. Gangwani, "Long-term effects of laparoscopic sleeve gastrectomy in morbidly obese subjects with type 2 diabetes mellitus," Surgery for Obesity and Related Diseases, vol. 6, no. 2, pp. 142-145, 2010.

[38] R. A. Weiner, S. Weiner, I. Pomhoff, C. Jacobi, W. Makarewicz, and G. Weigand, "Laparoscopic sleeve gastrectomy-influence of sleeve size and resected gastric volume," Obesity Surgery, vol. 17, no. 10, pp. 1297-1305, 2007.

[39] A. T. Y. Wong, D. C. Chan, J. Armstrong, and G. F. Watts, "Effect of laparoscopic sleeve gastrectomy on elevated C-reactive protein and atherogenic dyslipidemia in morbidly obese patients," Clinical Biochemistry, vol. 44, no. 4, pp. 342-344, 2011.

[40] O. Ou Yang, K. Loi, V. Liew, M. Talbot, and J. Jorgensen, "Staged laparoscopic sleeve gastrectomy followed by Roux-en-Y gastric bypass for morbidly obese patients: a risk reduction strategy," Obesity Surgery, vol. 18, no. 12, pp. 1575-1580, 2008.

[41] G. W. Strain, F. Zhang, W. Lei, G. F. Dakin, M. Gagner, and A. Pomp, "Changes in lipid profiles in morbidly obese patients after laparoscopic sleeve gastrectomy (LSG)," Obesity Surgery, vol. 21, no. 3, pp. 305-309, 2011.

[42] B. F. Asztalos, M. M. Swarbrick, E. J. Schaefer et al., "Effects of weight loss, induced by gastric bypass surgery, on HDL remodeling in obese women," Journal of Lipid Research, vol. 51, no. 8 , pp. 2405-2412, 2010. 


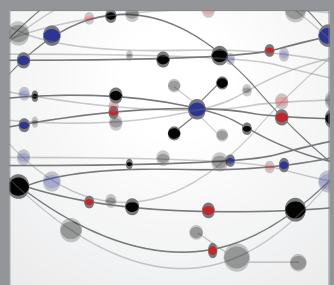

The Scientific World Journal
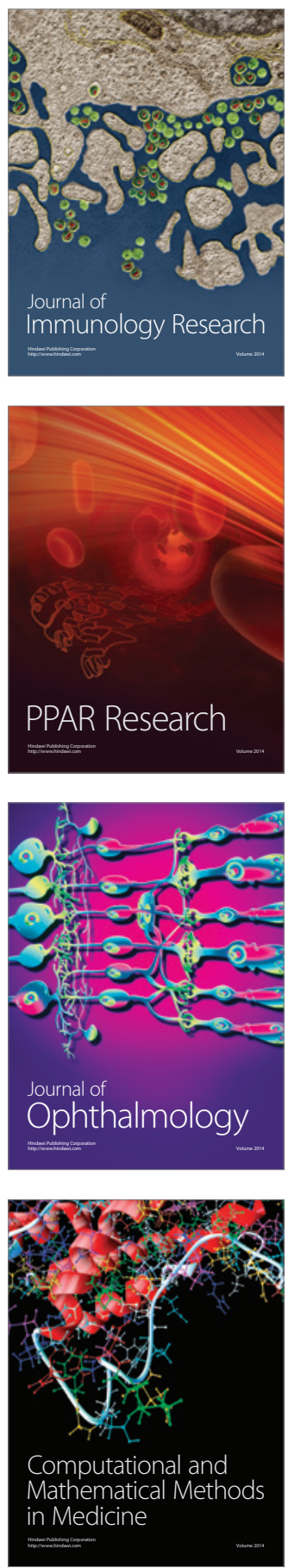

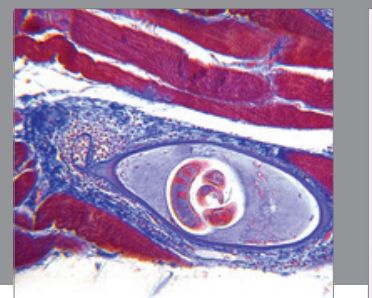

Gastroenterology

Research and Practice
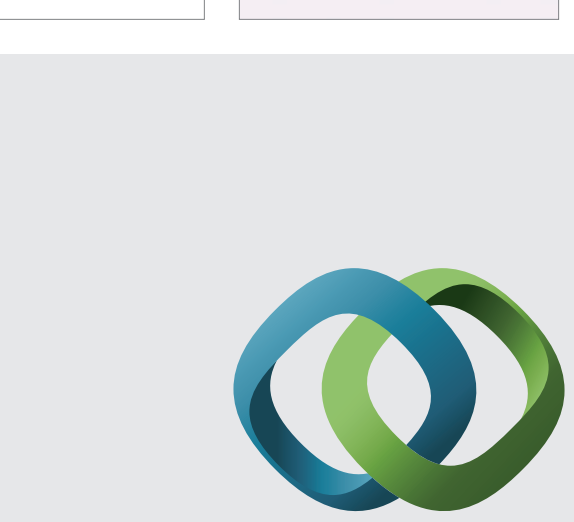

\section{Hindawi}

Submit your manuscripts at

http://www.hindawi.com
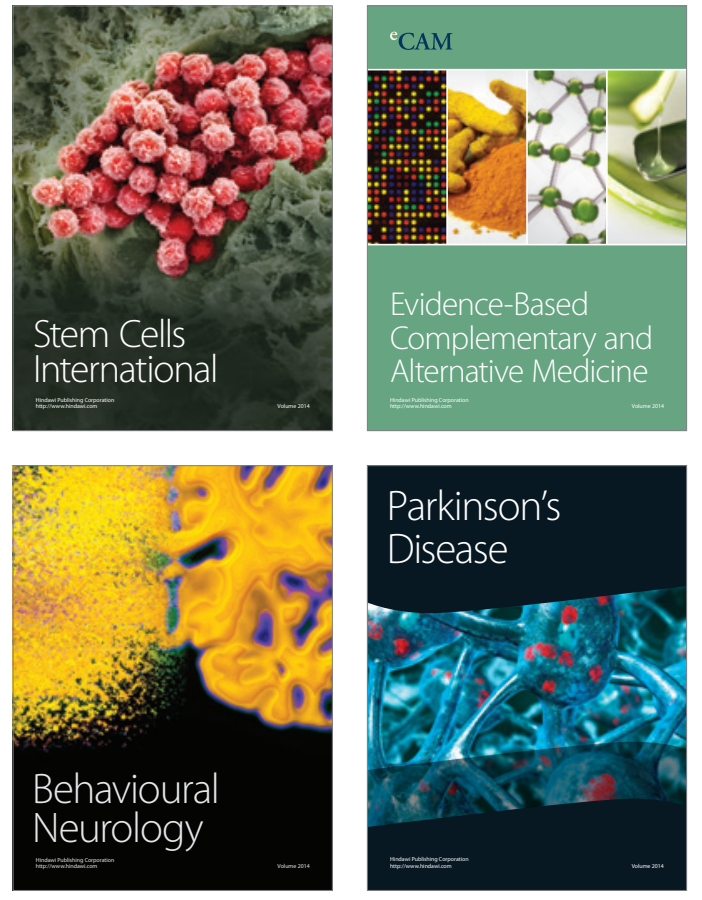
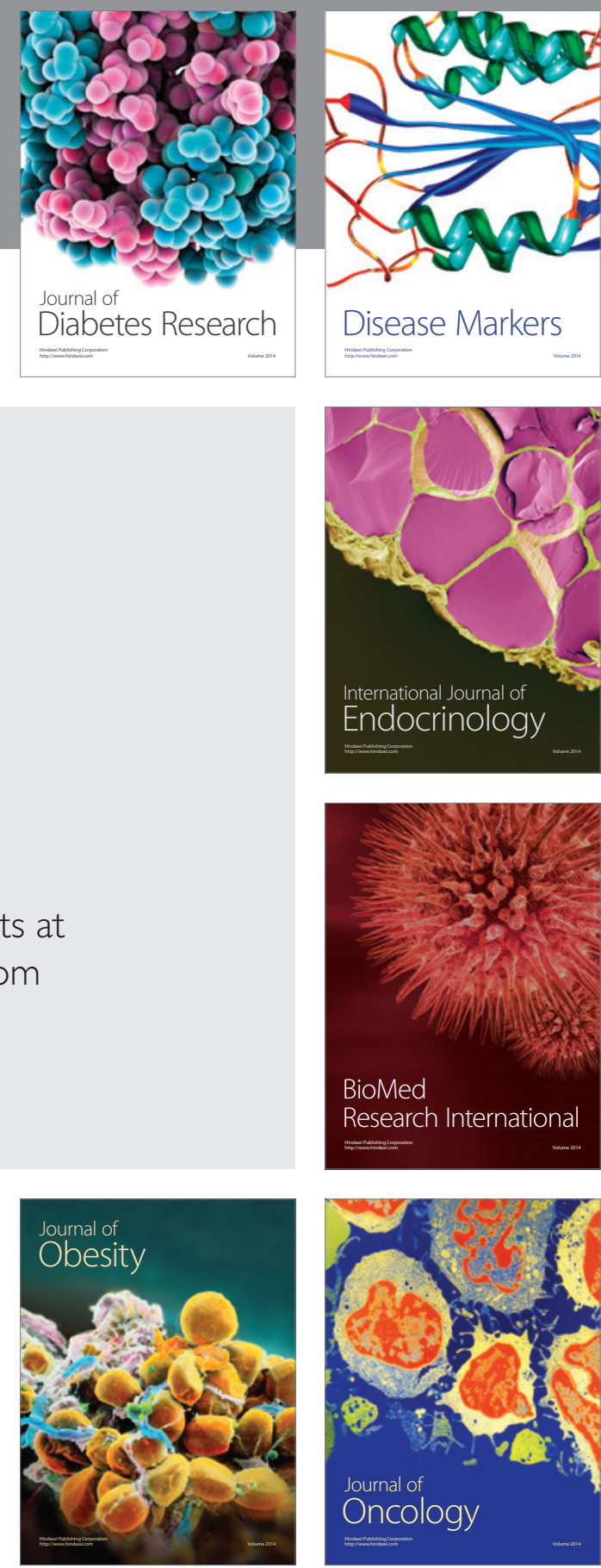

Disease Markers
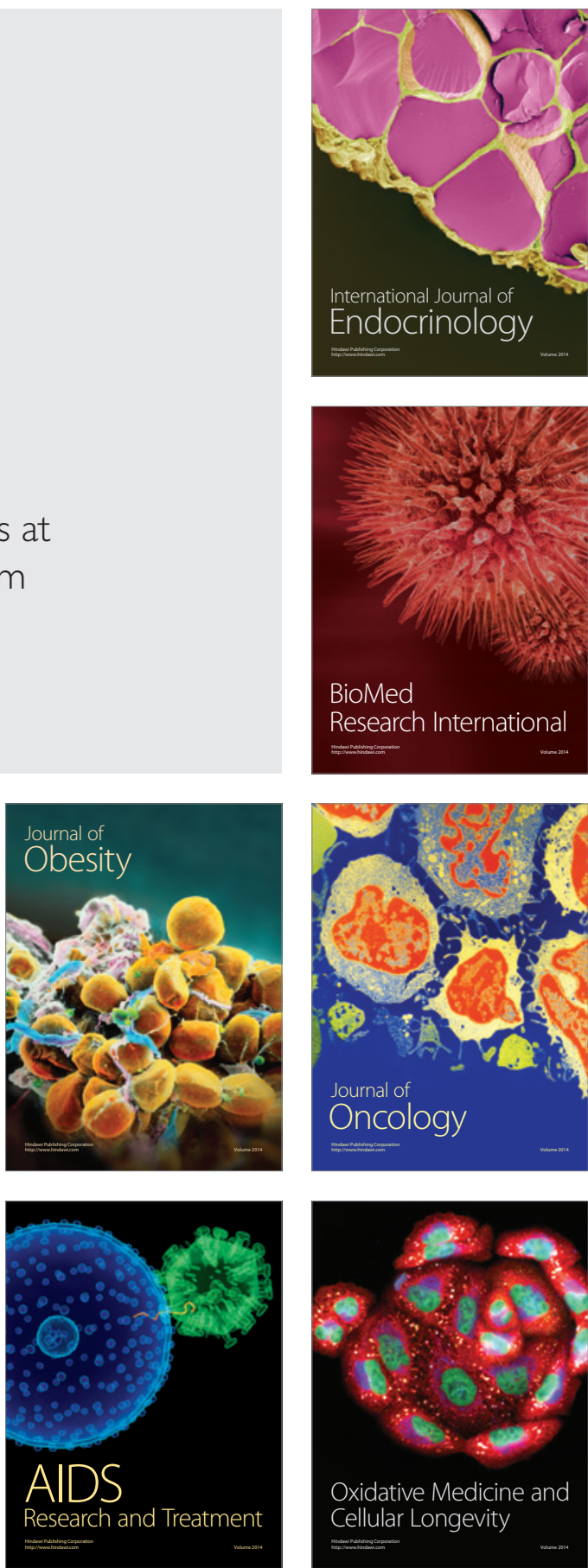